\title{
Incidence and Severity of Asiatic Citrus Canker on Diverse Citrus and Citrus-related Germplasm in a Florida Field Planting
}

Ed Stover², Randall Driggers, Matthew L. Richardson ${ }^{1}$, David G. Hall, and Yongping Duan

U.S. Horticultural Research Laboratory, U.S. Department of Agriculture, Agricultural Research Service, 2001 South Rock Road, Fort Pierce, FL 34945

\author{
Richard F. Lee \\ National Clonal Germplasm Repository for Citrus and Dates, U.S. \\ Department of Agriculture, Agricultural Research Service, 1060 Martin \\ Luther King Blvd, Riverside, CA 92521
}

Additional index words. Aurantioideae, Phyllocnistis citrella, resistance, Rutaceae, Toddalioideae, Xanthomonas citri ssp. citri

Abstract. Xanthomonas citri ssp. citri (Xcc) is the causal agent of Asiatic citrus canker (ACC), a commercially important disease in Florida citrus as well as in many other regions. In this study we evaluated occurrence of foliar lesions from ACC on progenies of 94 seed-source genotypes (hereafter called "parent genotypes") of Citrus and Citrus relatives in the field in east-central Florida to identify the relative susceptibility to ACC. Eight seedlings per parent genotype were planted in a randomized complete block planting, but the number of plants assessed in some genotype groups was reduced by mortality at some or all sampling dates. Plants experienced ambient exposure to high Xcc inoculum pressure and plants were assessed in Sept. 2010, July 2011, Oct. 2011, May 2012, and Sept. 2012. The incidence and severity of ACC lesions were assessed and evaluated using non-parametric analyses to compare progeny from the 94 parent genotypes. Progeny of 14 parent genotypes did not exhibit ACC symptoms at any date. All were in genera other than Citrus with only Microcitrus and Eremocitrus being crosscompatible with Citrus. The kumquat hybrid $C$. halimii, two accessions of $C$. reticulata, C. nobilis, and $C$. sunki were the only Citrus species in the group that had a low severity (percent total leaf area showing symptoms) on each date of assessment. The aforementioned accessions had an average incidence and severity of ACC lesions of less than $4 \%$ in 2011 and 2012, but $26 \%$ to $38 \%$ in 2010 when no chemical control for ACC was applied in the adjoining citrus groves at our field site. Fourteen of the 16 progeny of $C$. reticulata and related parent genotypes were in the group with the lowest incidence and severity of ACC on two or more assessment dates. However, for analysis of only the most symptomatic leaves on each plant, $10 \mathrm{C}$. reticulata parent genotype progenies were in the most resistant category on the Sept. 2012 assessment despite having a low incidence and severity of ACC symptoms overall. Progeny of Poncirus and its hybrids as well as those of $C$. maxima, $C$. limon, and related species were the most severely diseased at all assessment dates. There were few instances in which progeny of different accessions of the same species had markedly different responses to ACC: progeny of $\boldsymbol{C}$. reticulata 'Fremont' displayed more severe ACC compared with several other $C$. reticulata groups and $C$. aurantium 'Zhuluan' displayed much lower incidence and severity of ACC compared with several other accessions designated $C$. aurantium. Information on ACC susceptibility in diverse Citrus and Citrus relatives may prove useful for breeding programs aimed at reducing ACC susceptibility and will be of value to researchers interested in mechanisms of ACC resistance and susceptibility.

Asiatic citrus canker (caused by Xcc) was the focus of extensive eradication efforts in Florida until 2005 but is now widespread in Florida citrus (Gottwald et al., 2002; Irey et al., 2006). ACC is largely a disease of foliage and fruit that is spread primarily by wind-driven rain but can also be transferred by equipment and personnel (Gottwald et al., 2002). Wounds on leaves or fruit, including injury by the Asiatic citrus leafminer (CLM,
Phyllocnistis citrella Stainton), often greatly increases the severity of symptoms (Chagas et al., 2001; Christiano et al., 2007; Hall et al., 2010).

Genotypes of plants highly susceptible to ACC may have severe symptoms on leaves, twigs, and fruit; premature fruit and leaf drop; and have marked scarring on harvested fruit. Efforts to control ACC where it is prevalent include spraying trees frequently with protective chemical sprays (primarily copper products), constructing windbreaks to reduce spread by wind-driven rain, disinfecting equipment and personnel entering and leaving groves, managing CLM populations, and producing clean nursery stock in protective structures to prevent pathogen entry (reviewed by Gottwald et al., 2002). Citrus regions free of ACC, or without widespread infection, use extensive measures to avoid entry or spread of the pathogen. These measures have included prohibiting import of citrus from regions with ACC or the establishment, certification, and monitoring of ACC-free citrus production areas as a requirement for sale outside of infected areas (FDACS, 2009). This disease is of great economic significance and use of resistant cultivars would be highly advantageous in limiting injury associated with ACC and reducing the need for control measures. Therefore, in this study we assessed the severity of foliar ACC lesions on progeny from 94 parent genotypes of Citrus and relatives exposed to naturally occurring Xcc inoculum in the field in east-central Florida to identify their relative susceptibility to ACC.

\section{Materials and Methods}

Seeds for most progenies were obtained from the USDA-ARS National Clonal Germplasm Repository for Citrus and Dates located at the University of California at Riverside (UCR). Seeds were from fruit of field-grown trees in the Citrus Variety Collection of UCR (see http://www.citrusvariety. ucr.edu). Each accession in the Citrus Variety Collection is designated with a unique Citrus Research Center (CRC) number, providing access to history of each accession, taxonomic references, and confidence that the same material or resulting half-sib seedlings can be obtained for future work. All material tested was in the family Rutaceae and we obtained additional seed from the subfamily Aurantioideae (which includes Citrus), Afraegle paniculata (Schum.) Engl., and Aegle marmelos (L.) Corr. and from the subfamily Toddalioideae, Casimiroa edulis (Llave et Lex) from the Fruit and Spice Park (Miami/Dade County, FL) and Zanthoxylum ailanthoides (L.) from the University of Georgia.

Members of the Rutaceae vary greatly in their incidence of nucellar embryony (reviewed in Frost and Soost, 1968); therefore, some of the plants we tested were essentially genetically identical to the female parent (seeds serving as clonal propagules), whereas others were half-sib hybrids of known seed parents but with undetermined pollen parents. Hereafter, the seed parent accessions providing the progeny used in this study are referred to as "parent genotypes."

Seedling development, field planting, and general care were described in Richardson et al. (2011) and Westbrook et al. (2011) and were typical for citrus production except with minimal pesticide application. Most plants were germinated in Aug. 2008 and fieldplanted during June and July 2009, so in this 
study, plants were evaluated 3 to 5 years after germination.

Two chemical sprays were applied to the experimental block at the start of the experiment in 2010. One copper hydroxide spray (Kocide 2000 at $8.4 \mathrm{~kg} \cdot \mathrm{ha}^{-1}$; Dupont Crop Protection, Wilmington, DE) was applied on 13 July 2010 because ACC lesions were abundant and one foliar nutrient/copper spray (Magna-Bon at $20 \mathrm{mg} \cdot \mathrm{L}^{-1}$; Magna Bon International Inc. LLC, Okeechobee, FL) that is reported to suppress ACC was applied 10 Sept. 2010. No sprays were applied to the experimental plot in 2011 and 2012, but surrounding trees received Magna-Bon sprays every 3 to 4 weeks, which anecdotally appears to have reduced Xcc inoculum entering test plots.

Susceptibility of foliage to ACC differs markedly based on stage of leaf development when exposed to Xcc (Gottwald and Graham, 1992; Graham et al., 1992; Vernière et al., 2003) and even relatively resistant material may show small lesions. Because wind-driven rain is the primary factor distributing inoculum in standard citrus production (Graham et al., 1992), appropriate environmental conditions must coincide with foliage susceptibility for disease to develop. For these reasons, we quantified ACC in several ways to assess aspects of resistance that might be missed by estimating only the percent of leaf area affected by lesions (severity). ACC symptoms were assessed in Sept. 2010, July 2011, Oct. 2011, May 2012, and Sept. 2012. In 2010 , the incidence and the severity of symptoms of ACC were visually estimated across all leaves of each plant. Symptoms on young leaves, mature leaves, the most severely affected leaves, and an overall mean were quantified using a 6-point ordinal scale: $0=$ no visible lesions; $1=$ lesions present but slight; 2 = lesions obvious but not abundant; 3 = intermediate lesion abundance; $4=$ severe canker infection; and $5=$ leaves heavily covered in lesions. In 2011 only the percentage of total leaf surface displaying lesions on a plant was visually estimated, and this was also estimated in 2012. The visual estimates of leaf area diseased (ACC severity) were guided by a standard area diagram set (SADS)

Received for publication 30 Aug. 2013. Accepted for publication 30 Oct. 2013.

We thank Sean Reif, Diane Helseth, Philip Matonti, Scott Ciliento, and Jonathan Worton for assistance in the field and Zaid Abdo for advice on nonparametric correlations.

This article reports the results of research only. Mention of a trademark or proprietary product is solely for the purpose of providing specific information and does not constitute a guarantee or warranty of the product by the U.S. Department of Agriculture and does not imply its approval to the exclusion of other products that may also be suitable.

${ }^{1}$ Current address: Center for Conservation Education and Sustainability, Smithsonian Conservation Biology Institute, National Zoological Park, P.O. Box 37012, MRC 0705, Washington, DC 20013.

${ }^{2}$ To whom reprint requests should be addressed; e-mail Ed.Stover@ars.usda.gov. prepared using image analysis (Bock et al., 2010). SADS have been shown to greatly improve the accuracy and reliability of disease severity estimates of citrus canker in previous studies (Belasque et al., 2005). The incidence (percentage of leaves with lesions of ACC) and a second measure of severity (the percentage of leaf area diseased on the most severely affected leaves) were also estimated.

Statistical analyses. We tested whether the incidence and severity of ACC differed among progenies of the 94 parent genotypes using a non-parametric analysis: the F-approximation of the Friedman test (Ipe, 1987) and the associated rank sum multiple comparison test (PROC GLM; SAS Institute, Cary, NC).

Spearman correlations (PROC CORR; SAS Institute) were computed between CLM infestation (assessed 23 June, 2 Aug. 30 Aug., and 30 Sept. 2010) and ACC (assessed 28 Sept. 2010) on each tree. Specifically, we compared each of three measures of ACC (ACC severity averaged over all leaves, ACC severity on most severely infected leaves, and incidence of leaves with ACC lesions) for each tree with the mean CLM across the four dates (on a 0 to 3 scale with 3 the most infested; Richardson et al., 2011) . The same ACC measures were also correlated with maximum CLM measured per tree across the four sample dates in 2010. Correlations initially used data from all trees in the trial and were repeated after removing progeny genotypes that displayed no ACC.

\section{Results and Discussion}

ACC was widespread throughout the research farm where this experiment was conducted and ACC was evident throughout the trial planting. The bacterium Xanthomonas citri ssp. citrumelo is also present in Florida and produces similar symptoms but is only prevalent in nursery environments with frequent mechanical injury (budding and pruning) to trees (reviewed in Graham and Gottwald, 1991). Therefore, the distinctive canker lesions were attributed solely to Xanthomonas citri ssp. citri.

Progenies most resistant to ACC. Progeny of 14 parent genotypes were not observed to have ACC lesions at any date; these were all in genera other than Citrus with only Microcitrus and Eremocitrus cross-compatible with Citrus (Table 1). Progeny of 22 parent genotypes were in the statistical group least susceptible to ACC by each measure assessed: up to $8 \%$ of leaves displayed lesions but never had more than mild symptoms (Table 1). Again, this group of resistant progeny had no Citrus species. The kumquat hybrid $C$. halimii, two accessions of $C$. reticulata, C. nobilis, and C. sunki were the only Citrus species in the group that demonstrated the lowest severity of ACC on each date of assessment. However, these Citrus species were not in the least susceptible group when we quantified the incidence of ACC. Both measures of disease were less than $4 \%$ in
2011 and 2012 when the Xcc inoculum load was apparently reduced but were $26 \%$ to $38 \%$ in 2010 when Xcc inoculum pressure was very high. Progeny of 14 of 16 C. reticulata genotypes and related parent genotypes were in the group least affected by ACC at two or more times of assessment. Resistance of C. reticulata to ACC is frequently reported (e.g., Amaral et al., 2010). However, $10 C$. reticulata progenies were in the most susceptible category in Sept. 2012 when analyzed for lesion coverage on most symptomatic leaves despite having a low mean severity of ACC symptoms on all leaves (data not shown). There were only a few instances in which progeny of different accessions of the same species had marked differences in ACC response; progeny of the $C$. reticulata cultivar Fremont ('Clementine' $\times$ 'Ponkan') displayed more severe ACC symptoms compared with many other $C$. reticulata groups on several assessment dates.

One of the progeny groups (Naringi crenulata) apparently had a few small lesions that we did not score as ACC but were tested and verified as containing Xcc by a collaborator at the Florida Department of Agriculture and Consumer Services (S. Halbert, personal communication). This was reported as the first documented instance of ACC on $N$. crenulata. Because there were only a few lesions on one plant, even if this minor discrepancy was repeated on other genera related to Citrus, it would have a negligible effect on the results in this report.

Progenies most susceptible to ACC. Progeny of Poncirus and its hybrids as well as those of $C$. maxima, $C$. limon, and related species dominated the most symptomatic group at all assessment times and in all parameters measured (Table 1). Progenies from some individual accessions of $C$. medica (CRC 3546) and C. maxima (CRC 3959) were less consistently in the most susceptible group, but they were not significantly different from other populations within the same species in our study. Progenies from accessions of C. aurantium displayed the greatest variability for ACC susceptibility within the same species: 'Zhuluan' (CRC 3930) displayed much lower susceptibility than several other accessions (CRC 2717, CRC 628). However, the identity of 'Zhuluan' is somewhat uncertain: it is labeled a sour orange hybrid in the University of California citrus variety collection but as a standard sour orange in other publications (Bernet et al., 2008). 'Lakeland' limequat (C. aurantifolia $\times$ Fortunella japonica) is reported to be resistant to citrus canker and with great potential as a parent for breeding resistant scions (Viloria et al., 2004), but in this study, progeny of the closely related 'Tavares' limequat (C. aurantifolia $\times$ Fortunella margarita) were consistently in the most susceptible group. In a greenhouse study, 'Lakeland' limequat is also reported to be moderately resistant, whereas its full sib 'Eustis' limequat is scored as highly susceptible (Amaral et al., 2010). Fortunella species are reported to be among the most resistant Citrus relatives 


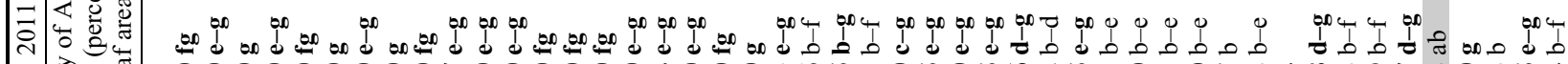

ـ

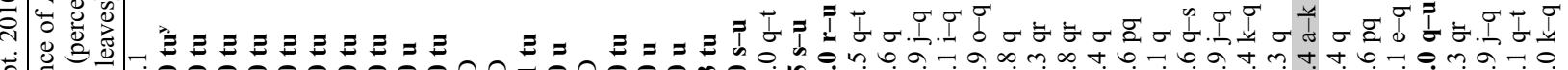
总 迏要

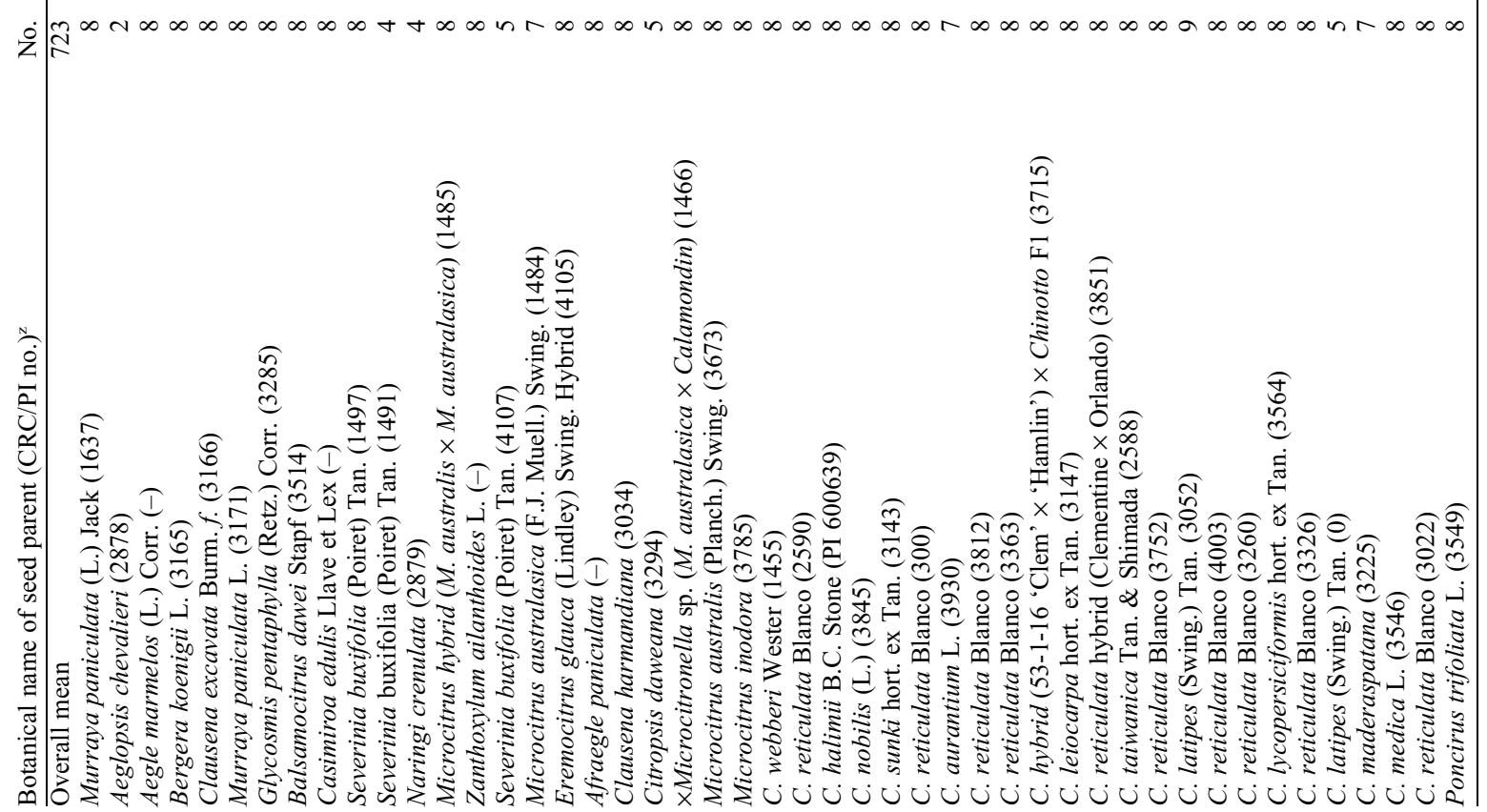




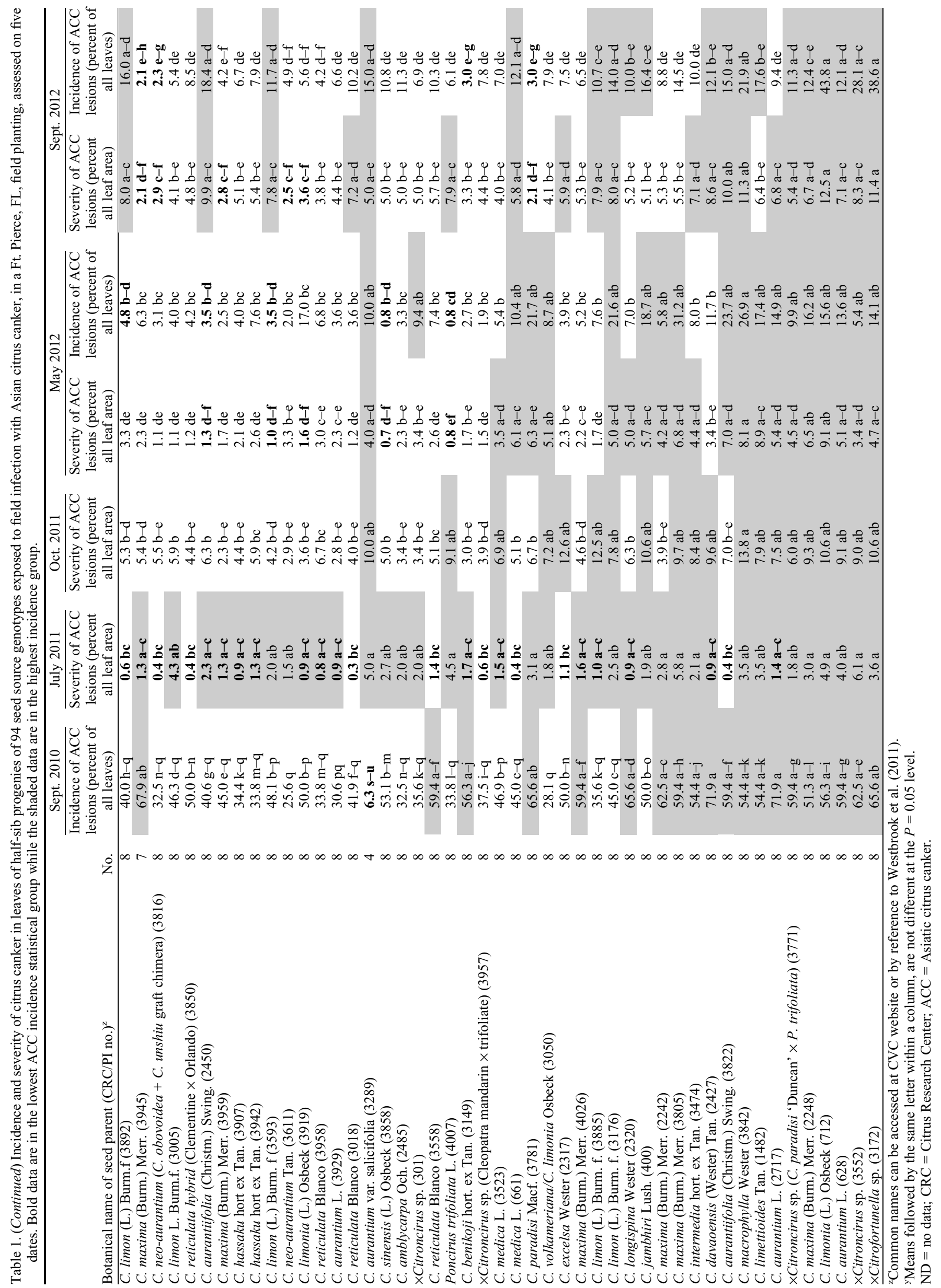


to ACC, whereas C. aurantifolia is consistently among the most susceptible (Brunings and Gabriel, 2003; Khalaf et al., 2007).

Comparison of measures of ACC Susceptibility and susceptibility of progeny between years. When Xcc inoculum pressure was very high and lesions were extremely abundant in 2010, severity of ACC on mature leaves, young leaves, most severely affected leaves, and all leaves was scored on a 6-point scale. Relative susceptibility of the progeny and means separation were essentially identical across all the ways we quantified ACC as was the percentage of leaves displaying lesions (data not shown).

Severity of ACC per leaf (percentage of leaf area diseased) was assessed on all leaves and on the most symptomatic leaves at both assessment times in 2012. We also calculated the incidence of ACC (percentage of leaves displaying lesions). Lesions of ACC were somewhat suppressed in 2012 (across the entire experiment, $8 \%$ of leaves were diseased in the fall in 2012 vs. $34 \%$ in 2010). However, ranking and mean separations for incidence and severity of ACC were very similar. The severity on the most symptomatic leaves was fairly high $(5 \%$ to $18 \%$ in most progenies) in September with little means separation between progenies of parent genotypes scored overall as moderately susceptible and highly susceptible to ACC (data not shown). This may simply reflect leaves that were unprotected when leaf development, environmental conditions, and inoculum were suitable for infection.

The relative ranking of the progeny in ACC susceptibility was very similar in each of the 3 years of evaluations despite contrasting Xcc inoculum pressure. This robustness provides greater confidence that the differences observed are biologically relevant and may be useful for breeders when making germplasm selection decisions to improve ACC resistance.

Contrasting results with previous literature. A number of published studies assessed the susceptibility of Citrus and Citrus relatives to ACC. Peltier (1918) conducted one of the first published studies assessing ACC resistance using spray inoculations on 59 accessions of Citrus and relatives in greenhouse and field plots in Alabama. For genera related to Citrus, his results agree with our finding of no visible ACC symptoms in Xanthoxylum, Casimiroa, Glycosmis, Aegle, Aeglopsis, Hesperethusa, and Microcitrus as well as extreme susceptibility in Poncirus. However, he reports that Eremocitrus glauca is highly susceptible, whereas the progeny from the parent genotype we used developed very few lesions. Our results also agree with Peltier's reports for the seven Citrus and Citrus hybrids shared in the two studies.

Reddy (1997) evaluated 144 Citrus and Citrus relatives in India for ambient infection with Xcc. He reported no visible symptoms in three species/cultivars shared between our studies: Microcitrus australis, Severenia buxifolia, and Sunki mandarin (C. sunki). However, a low incidence of ACC, rather than no symptoms, was observed on trees of these parent genotypes in our study.

In a Florida study, pinprick inoculations of leaves with Xcc resulted in lesions on virtually all of 54 accessions tested, and lesion size did not vary greatly between accessions, except that Murraya paniculata, Fortunella margarita, and Severinia buxifolia had significantly smaller lesions (Gottwald et al., 1993). These were the only three distant Citrus relatives shared with our study, and we observed no evidence of canker in progenies of these parent genotypes. Gottwald et al. (1993) note that the wound inoculation of the pinprick method apparently obscured differences observed in the field.

Forced infiltration of Xcc through stomates was used to compare lesion number in eight diverse commercial genotypes (Graham et al., 1992). P. trifoliata, Carrizo citrange (C. sinensis $\times P$. trifoliata), and Cleopatra mandarin $(C$. reticulata $)$ displayed significantly fewer lesions than several commercial genotypes but still produced many lesions (Graham et al., 1992). In our study, Carrizo citrange and Cleopatra mandarin were not included, and the two progenies of Poncirus trifoliata parent genotypes were in the most susceptible category based on severity of ACC in July 2011 and Sept. 2012 but in the least susceptible category in May 2012.

In a Brazilian greenhouse study, 582 accessions were pruned to produce a uniform flush and were spray-inoculated with Xcc when some leaves on each plant were $6 \%$ to $80 \%$ expanded (Amaral et al., 2010). This study focused primarily on commercial scion types and found $13 \%$ of all accessions to be resistant ( $0 \%$ to $5 \%$ of leaf area diseased) and $42 \%$ to be moderately resistant (5\% to $10 \%$ of leaf area diseased). Cultivars of sweet orange (C. sinensis) were distributed in each category from resistant to highly susceptible with variant strains within 'Pera' sweet orange, 'Valencia' sweet orange, and grapefruit (C. paradisi) showing marked differences (some resistant and some highly susceptible), although sweet orange and grapefruit are each near isogenic (Fang and Roose, 1997). For the seven genotypes in that study that by name appear to also be parent genotypes in our comparison, we find similar resistance for M. paniculata (Orange Jessamine), C. nobilis (King mandarin), and C. webberi (Kalpi papeda), but they report as moderately resistant several genotypes from which progenies were consistently in the most susceptible category in our field study ('Lisbon' lemon = C. limon, 'Kao' pummelo $=C$. maxima, and sweet lime $=C$. aurantifolia). Greenhouse experiments have the advantage of avoiding certain confounding factors in the field such as CLM enhancing spread of ACC but provide only a single exposure to Xcc, unlike the virtually continuous exposure observed in the field. Additionally, the accessions in the greenhouse were only assessed once, 4 weeks after inoculation.

Progenies of the parent genotypes $C$. medica and C. maxima were among the most consistently susceptible in our study.
However, only one accession of $C$. medica was tested in China and was the most resistant to ACC out of all the material evaluated, and citrons ( $C$. medica) were anecdotally reported to routinely show ACC resistance (Deng et al., 2010). There are other reports from Florida of C. medica displaying susceptibility to ACC (Gottwald et al., 1993), which is in agreement with our study. A Pakistani report indicated that most lemons $(C$. limon, which are $C$. medica hybrids, and were highly susceptible in our study) were resistant to all but one isolate of Xcc tested (Prasad et al., 1997). A second report from Pakistan also indicated that the one $C$. maxima accession tested displayed no ACC symptoms (Sarkar et al., 2007). These discrepancies may reflect diversity in Citrus germplasm or diversity of Xcc strains resulting in marked strain $\times$ genotype interactions.

Relationship between citrus leaf miner infestation and ACC. Severity of ACC within individual cultivars is enhanced by CLM injury to leaves (Hall et al., 2010). The field plot used for this experiment was also used to identify the relative abundance of larval CLM, as previously reported (Richardson et al., 2011), with data collected in 2010 coincident with some of the ACC data reported here. This provided the opportunity to assess the association between CLM infestation and ACC severity in this trial. Spearman non-parametric correlation coefficients between CLM infestation (assessed 23 June, 2 Aug., 30 Aug., and 30 Sept. 2010) and ACC severity (assessed 28 Sept. 2010) are presented in Table 2 with all correlations highly significant $(P=0.0045$ to $<0.0001)$. When correlations were conducted on all trees in the trial, the correlation coefficients ranged from 0.51 to 0.53 for the parameters compared, indicating a fairly strong association. However, many of the distant Citrus relatives that showed no ACC symptoms also displayed no CLM infestation (Richardson et al., 2011), which greatly influenced the strength of the correlation observed. When trees with no ACC were excluded, correlation coefficients ranged from 0.12 to 0.18 for the parameters compared. This was still a positive correlation but suggested that CLM presence may not have greatly influenced the relative susceptibility of accessions to ACC. Interestingly, $P$. trifoliata and hybrids are moderately to highly resistant to CLM but display high susceptibility to ACC.

Caution and conclusion. This study provides data on relative susceptibility of Citrus and Citrus relatives to ACC. Relative susceptibility to ACC differed greatly among progenies of accessions of Citrus and related genera, and this relative susceptibility was consistent over 3 years and across several ways of quantifying ACC. There are reports of at least three genetically different isolates of Xcc in Florida (Cubrero and Graham, 2002) and likely many more around the world. Accessions of Citrus and relatives may differentially respond to these isolates of Xcc, and this is likely given the conflicting reports on susceptibility within the primary 
Table 2. Spearman rank correlation between citrus leaf miner (CLM) infestation (assessed 23 June, 2 Aug., 30 Aug., and 30 Sept. 2010) and Asiatic citrus canker (ACC) severity (assessed 28 Sept. 2010) on each tree in replicated half-sib families of 94 seed source genotypes of Citrus and relatives in a germplasm trial in Ft. Pierce, FL. ${ }^{z}$

\begin{tabular}{clccc}
\hline & $\begin{array}{c}\text { Mean ACC } \\
\text { severity }\end{array}$ & $\begin{array}{c}\text { ACC severity } \\
\text { on worst leaves }\end{array}$ & $\begin{array}{c}\text { Percentage } \\
\text { of leaves with } \\
\text { ACC lesions }\end{array}$ \\
\hline All trees $(\mathrm{n}=697)$ & Mean CLM & 0.53 & 0.51 & 0.52 \\
Only trees with & Maximum CLM & 0.56 & 0.56 & 0.53 \\
ACC $(\mathrm{n}=559)$ & Mean CLM & 0.18 & 0.12 & 0.15 \\
& Maximum CLM & 0.18 & 0.18 & 0.12 \\
\hline
\end{tabular}

${ }^{2}$ Comparisons are between mean CLM (on a 0 to 3 scale with 3 the most infested; Richardson et al., 2011) and ACC severity averaged over all leaves or the most severely infected leaves (on a 0 to 5 scale with 5 the most infected) or percentage of leaves estimated to show any ACC lesions as well as correlations between maximum CLM rating per tree and each measure of ACC severity. Correlations were conducted on all trees in the trial and also were separately conducted only on trees displaying some ACC lesions. All correlations were significant at $P<0.0001$ to 0.0045 .

literature. Therefore, our results are most relevant within the context of Xcc isolates present in the Indian River region of Florida. Information on relative susceptibility of diverse Citrus and Citrus relatives to ACC may prove useful in breeding programs aimed at reducing susceptibility and may provide useful guidance for researchers interested in mechanisms of resistance and susceptibility.

\section{Literature Cited}

Amaral, A.M., S.A. Carvalho, L.F.C. Silva, and M.A. Machado. 2010. The reaction of genotypes of Citrus species and varieties to Xanthomonas citri ssp. citri under greenhouse conditions. J. Plant Pathol. 92:519-524.

Belasque, J., Jr., R.B. Bassanezi, M.B. Spósito, L.M. Ribeiro, W.C. de Jesus, Jr., and L. Amorim. 2005. Escalas diagramáticas para avaliação da severidade do cancro cítrico. Fitopatol. Bras. 30:387-393.

Bernet, G.P., M.T. Gorris, E.A. Carbonell, M. Cambra, and M.J. Asins. 2008. Citrus tristeza virus resistance in a core collection of sour orange based on a diversity study of three germplasm collections using QTL-linked markers. Plant Breed. 127:398-406.

Bock, C.H., G.H. Poole, P.E. Parker, and T.R. Gottwald. 2010. Plant disease severity estimated visually, by digital photography and image analysis, and by hyperspectral imaging. Crit. Rev. Plant Sci. 29:59-107.

Brunings, A.M. and D.W. Gabriel. 2003. Xanthomonas citri: Breaking the surface. Mol. Plant Pathol. 4:141-157.

Chagas, M.C.M., J.R.P. Parra, T. Namekata, J.S. Hartung, and P.T. Yamamoto. 2001. Phyllocnistis citrella Stainton (Lepidoptera: Gracillariidae) and its relationship with the citrus canker bacterium Xanthomonas axonopodis pv citri in Brazil. Neotrop. Entomol. 30:55-59.

Christiano, R.S.C., M.D. Pria, W.C. Jesus Jr., J.R.P. Parra, L. Amorim, and A. Bergamin Filho. 2007. Effect of citrus leaf-miner damage, mechanical damage, and inoculum concentration on severity of symptoms of Asiatic citrus canker in Tahiti lime. Crop Prot. 26:59-65.

Cubrero, J. and J.H. Graham. 2002. Genetic relationship among worldwide strains of Xanthomonas causing canker in citrus species and design of new primers for their identification by PCR. Appl. Environ. Microbiol. 66:12571264.

Deng, Z.N., D.Z. Li, G.Y. Long, L.P. Liu, F. Fang, L. Xu, and G.P. Shu. 2010. Screening citrus genotypes for resistance to canker disease (Xanthomonas axonopodis pv. citri). Plant Breed. 129:341-345.

Fang, D.Q. and M.L. Roose. 1997. Identification of closely related citrus cultivars with intersimple sequence repeat markers. Theor. Appl. Genet. 95:408-417.

FDACS. 2009. Fresh fruit shipment procedures effective 22 Oct. 2009. Version 2.0. 5 Aug. 2013. <http://www.freshfromflorida.com/pi/ chrp/documents/Fresh\%20Fruit\%20Shipment $\%$ 20Procedures $\% 2010-22-09 \% 20$ Ver $\% 202 \% 200$. pdf $>$.

Frost, H.B. and R.K. Soost. 1968. Seed reproduction: Development of gametes and embryos, $p$. 290-324. In: Reuther, W., L.D. Batchelor and H.J. Webber (eds.). The citrus industry. Vol. 2. Anatomy, physiology, genetics, and reproduction. Univ. California, Berkeley, CA.

Gottwald, T.R. and J.H. Graham. 1992. A device for precise and nondisruptive stomatal inoculation of leaf tissue with bacterial pathogens. Phytopathology 82:930-935.

Gottwald, T.R., J.H. Graham, E.L. Civerolo, H.C. Barrett, and C.J. Hearn. 1993. Differential host range reaction of citrus and citrus relatives to citrus canker and citrus bacterial spot determined by leaf mesophyll susceptibility. Plant Dis. 77:1004-1009.

Gottwald, T.R., J.H. Graham, and T.S. Schubert. 2002. Citrus canker: The pathogen and its impact. Plant Health Progress (August). p. 1-32. 5 Aug. 2013. <http://www.plantmanagementnetwork. org/pub/php/review/citruscanker/>.
Graham, J.H. and T.R. Gottwald. 1991. Research perspectives on eradication of citrus bacterial diseases in Florida. Plant Dis. 75:1193-1200.

Graham, J.H., T.R. Gottwald, T.D. Riley, and D. Achor. 1992. Penetration through leaf stomata and growth of strains of Xanthomonas campestris in citrus cultivars varying in susceptibility to bacterial diseases. Phytopathology 82:1319-1325.

Hall, D.G., T.R. Gottwald, and C.H. Bock. 2010. Exacerbation of citrus canker by citrus leafminer Phyllocnistis citrella in Florida. Fla. Entomol. 93:558-566.

Ipe, D. 1987. Performing the Friedman test and the associated multiple comparison test using PROC GLM. Proc. Twelfth Annu. SAS Users Group Int. Conf. SAS Institute, Cary, NC. p. 1146-1148.

Irey, M., T.R. Gottwald, J.H. Graham, T.D. Riley, and G. Carlton. 2006. Post-hurricane analysis of citrus canker spread and progress towards the development of a predictive model to estimate disease spread due to catastrophic weather events. Plant Health Prog. (August):1-12.

Khalaf, A., G.A. Moore, J.B. Jones, and F.G. Gmitter, Jr. 2007. New insights into the resistance of Nagami kumquat to canker disease. Physiol. Mol. Plant Pathol. 71:240-250.

Peltier, G.L. 1918. Susceptibility and resistance to citrus-canker of the wild relatives, citrus fruits and hybrids of the genus Citrus. J. Agr. Res. 9:337-345.

Prasad, M.B., N.V.R. Singh, A. Rekha, and R. Chand. 1997. Evaluation of lemon cultivars and acid lime $\times$ lemon hybrids for resistance to Xanthomonas axonopodis pv. citri. Sci. Hort. 71:267-272.

Reddy, M.R.S. 1997. Sources of resistance to bacterial canker in citrus. J. Mycol. Plant Pathol. 27:80-81.

Richardson, M.L., C.J. Westbrook, D.G. Hall, E.W. Stover, Y.P. Duan, and R.F. Lee. 2011. Abundance of the citrus leafminer on Citrus and Citrus-related germplasm. HortScience 46:1260-1264.

Sarkar, J., J. Saha, B.N. Panja, and A. Das. 2007. Evaluation of Citrus species and their relatives of tolerance to bacterial canker disease and prediction of canker incidence based on leaf morphological characters. J. Mycopathol. Res. 45:175-181.

Vernière, C.J., T.R. Gottwald, and O. Pruvost. 2003. Disease development and symptom expression of Xanthomonas axonopodis pv. citri in various citrus plant tissues. Phytopathology 93:832-843.

Viloria, Z., D.L. Drouillard, J.H. Graham, and J.W. Grosser. 2004. Screening triploid hybrids of 'Lakeland' limequat for resistance to citrus canker. Plant Dis. 88:1056-1060.

Westbrook, C.J., D.G. Hall, E.W. Stover, Y.P. Duan, and R.F. Lee. 2011. Colonization of Citrus and Citrus-related germplasm by Diaphorina citri (Hemiptera: Psyllidae). HortScience 46:1-9. 